\title{
Fixação biológica de nitrogênio por plantas de trevo (Trifolium spp) em sistema de integração lavoura-pecuária no Sul do Brasil
}

\section{Tangriani Simioni Assmann ${ }^{1}$, Alceu Luiz Assmann², André Brugnara Soares ${ }^{1}$, Luís César Cassol $^{1}$, Margareth Steiner Giasson ${ }^{3}$, Nizio Fernando Giasson ${ }^{3}$}

\footnotetext{
${ }^{1}$ Curso de Agronomia da Universidade Tecnológica Federal do Paraná (UTFPR), Campus Pato Branco.

2 Instituto Agronômico do Paraná (IAPAR), Pato Branco/PR.

${ }^{3}$ Engenheiro Agrônomo, ex Bolsista PIBIC/CNPq.
}

RESUMO - Este trabalho foi realizado com o objetivo de avaliar o efeito da inclusão de plantas de trevo (Trifolium spp) sob pastejo em sistema de integração lavoura-pecuária sobre a quantidade de $\mathrm{N}$ fixada, a produtividade, os componentes de rendimento da cultura de milho e os teores de nitrato no solo. O delineamento utilizado foi de blocos ao acaso, com três repetições, em que as parcelas foram constituídas dos resíduos de espécie forrageira (trevo e aveia) e as subparcelas, das quatro doses de N em cobertura (0; 60; 120; e $240 \mathrm{~kg} / \mathrm{ha}$ ). Durante o período de cultivo do milho (2004/2005), as parcelas contendo resíduo de trevo apresentaram maiores de teores de $\mathrm{N}$-nitrato na profundidade de $0-5 \mathrm{~cm}$ em comparação àquelas cultivadas anteriormente com aveia, indicando que a cultura de milho encontraria praticamente todo o suprimento de nitrogênio, em decorrência do cultivo anterior de trevos pastejados. Não foram observados indícios de lixiviação de nitratos provocados pelos resíduos de leguminosas até a camada de $20 \mathrm{~cm}$ de profundidade do solo. No segundo ano de experimento, plantas de trevo pastejadas contribuíram, no mínimo, com suprimento de $\mathrm{N}$ de $90 \mathrm{~kg} / \mathrm{ha}$, como resultado da fixação biológica para a cultura de milho. No entanto, plantas de milho cultivadas sobre resíduos de aveia apresentaram máxima produtividade de grãos com aplicação de $180 \mathrm{~kg} / \mathrm{ha}$ de $\mathrm{N}$.

Palavras-chave: aveia, nitrato, componentes de rendimento, máxima eficiência técnica de N

\section{Nitrogen biological fixation by clover plants (Trifolium spp) on crop-pasture systems in southern Brazil}

\begin{abstract}
The objective of this research was to study the effect of including grazed clover plants, in crop-pasture systems, on the amount of $\mathrm{N}$ fixed, maize productivity and yield components, and soil nitrate concentration. It was used a split-plot arrangement in a complete randomized block design, with three replications per treatment. The main plots were formed by two types of residues of winter pastures (oat and clover) and the split-plots were formed by different doses of broadcasted $\mathrm{N}$ in the urea form $(0,60,120$, and $240 \mathrm{~kg} / \mathrm{ha} \mathrm{N})$. The effect of the previous residue was observed during all periods of the corn crop (2004/2005). All plots that contained clover residue presented greater N-nitrate concentration in the soil layer of 0-5 cm compared to those plots cultivated previously with oats. These results showed that the white clover residues after grazing would provide practically all nitrogen demand by the maize crop. It was not observed nitrate leaching caused by legume residues until the depth of $20 \mathrm{~cm}$. In the second experimental year, the clover residue contributed, at the very least, with $90 \mathrm{~kg} / \mathrm{ha}$ of $\mathrm{N}$, resultant from the $\mathrm{N}$ biological fixation, to the corn crop. However, maize plants cultivated on oat residual mulch showed maximum grain yield under $180 \mathrm{~kg} / \mathrm{ha}$ of $\mathrm{N}$-fertilizer.
\end{abstract}

Key Words: nitrate, $\mathrm{N}$ maximum technical efficiency, oat, yield components

\section{Introdução}

A adubação nitrogenada foi identificada como o fator de maior índice de consumo de energia para produção agrícola (Ma \& Dwyer, 1998). O desenvolvimento de estratégias de aplicação e reciclagem de $\mathrm{N}$ é importante para melhorar a eficiência de uso do elemento e aumentar as taxas de lucro de produtores sem provocar contaminações ambientais. A aplicação racional de $\mathrm{N}$ deve equilibrar a eficiência energética e a proteção ambiental enquanto aumenta a lucratividade e a qualidade alimentar (Schröder et al., 2000).

A inclusão de leguminosa de inverno em sistemas exclusivamente agrícolas tem sido adotada no Sul do Brasil como alternativa para redução da adubação nitrogenada para as culturas de verão, principalmente o milho. No entanto, este estudo tem se restringindo a espécies como a ervilhaca (Vicia vilosa) e poucas informações são dispo- 
níveis em relação a leguminosas perenes, especialmente trevos (Trifolium spp), gênero que mais se destaca no Sul do Brasil pela resistência ao pastejo.

Existe grande variação na quantidade de $\mathrm{N}_{2}$ fixado por todas as espécies de leguminosas. Por exemplo, no trevobranco (Trifolium repens), esta quantidade de $\mathrm{N}$ pode chegar a mais de $500 \mathrm{~kg} / \mathrm{ha} / \mathrm{ano}$. Contudo, a quantidade usual de fixação de $\mathrm{N}$ no consórcio gramínea-trevos na Nova Zelândia varia de 85 a 350 kg/ha de N (Hoglund et al., 1979; Caradus, 1990; Ledgard et al., 1990).

Estudos para avaliação de fontes enriquecidas com ${ }^{15} \mathrm{~N}$ comprovaram que os resíduos de leguminosas contribuem com pequenas a moderadas quantidades de $\mathrm{N}$ (de 4 a $25 \%$ do $\mathrm{N}$ contido nos resíduos) no primeiro cultivo subseqüente, em comparação à contribuição do $\mathrm{N}$ proveniente de fertilizantes, de 40 a 50\% (Ta \& Faris, 1990). Apesar de a contribuição de $\mathrm{N}$ de ambas as fontes diminuir significativamente no segundo cultivo ( $<5 \%$ da quantidade de $\mathrm{N}$ adicionada), leguminosas geralmente suprem mais $\mathrm{N}$ que os fertilizantes no segundo e subseqüentes cultivos.

Armstrong et al. (1998) constataram que a recuperação de $\mathrm{N}$ pelas plantas de trigo (primeiro cultivo) foi de $35 \%$ do $\mathrm{N}$ adicionado por fertilizantes e apenas de $5 \%$ do $\mathrm{N}$ proveniente de resíduos vegetais. A absorção de $\mathrm{N}$ pelas culturas foi diretamente proporcional às quantidades presentes nos resíduos vegetais e nos fertilizantes adicionados e inversamente proporcional à quantidade de resíduos aplicados, fato atribuído à imobilização do $\mathrm{N}$ durante a decomposição dos resíduos e à incorporação do carbono na matéria orgânica do solo. Contudo, quando avaliados consecutivamente quatro cultivos, o efeito inicial da redução de absorção de N, provocado pela quantidade de resíduo adicionado, não foi mais observado. Esse resultado era esperado, uma vez que a imobilização de $\mathrm{N}$ pode ocorrer apenas quando os resíduos adicionados decompõem, porém, subseqüentemente, parte do N imobilizado pode ser re-mineralizada para cultivos posteriores.

Uma das principais dificuldades em pesquisas com trevos é mantê-los em quantidade suficiente, especialmente quando cultivado em consórcio, a fim de que a espécie contribua significativamente com o fornecimento de $\mathrm{N}$ para plantas cultivadas seqüencialmente. Boller \& Nösberger (1987) sugeriram três condições básicas para se atingir fixação de $\mathrm{N}$ superior a $200 \mathrm{~kg} / \mathrm{ha} /$ ano pelo trevo em consórcio: a) as condições climáticas e de solo devem permitir produção de massa seca superior a $10.000 \mathrm{~kg} / \mathrm{ha} /$ ano; b) a proporção de trevo presente no consórcio deve ser de pelo menos $50 \%$; e c) no mínimo $70 \%$ do $\mathrm{N}$ total presente no trevo deve ser proveniente da fixação biológica.
Em estudo realizado em Guarapuava-PR, Assmann et al. (2003) e Assmann et al. (2004) não observaram efeito da inclusão desta leguminosa em consórcio com gramíneas sobre a produção animal ou a produção de milho cultivado em seqüência e atribuíram o fato a adversidades climáticas que reduziram a população de trevo branco na área.

Em condições brasileiras, são poucos os estudos sobre o potencial de fixação de $\mathrm{N}$ por plantas de trevo, conhecimento fundamental para o estabelecimento de sistemas de produção mais sustentáveis. Este trabalho se baseou na hipótese de que a presença de trevo-branco contribui com aporte de $\mathrm{N}$, o que dispensaria, parcial ou totalmente, a adubação nitrogenada no verão. Assim, objetivou-se verificar o efeito residual e a fixação biológica do nitrogênio por plantas de trevo para o milho cultivado em áreas onde houve a combinação de doses de $\mathrm{N}$ com a presença de trevos.

\section{Material e Métodos}

O experimento foi instalado no inverno de 2003 na Estação Experimental do Instituto Agronômico do Paraná - IAPAR, localizada em Pato Branco - PR. A área experimental está localizada na região fisiográfica denominada Terceiro Planalto Paranaense e encontra-se entre as coordenadas $25^{\circ} 07^{\prime}$ Sul e $52^{\circ} 41^{\prime}$ Oeste com altitude média de $700 \mathrm{~m}$. O solo do local é classificado como Latossolo Vermelho relevo ondulado de textura argilosa (Tabela 1) e o clima da região, segundo classificação de Köppen, é de transição entre Cfb e Cfa (Maak, 1968). A precipitação pluviométrica dos últimos dez anos tem variado de 1.578 a $3.101 \mathrm{~mm}$ por ano, com temperatura máxima de $25^{\circ} \mathrm{C}$ e mínima de $14,2^{\circ} \mathrm{C}$.

A área experimental tem sido utilizada em sistema de plantio direto há mais de dez anos. Durante o verão, foram feitos cultivos alternados de milho e soja e no inverno foi utilizada rotação com cereais e nabo forrageiro.

O experimento foi conduzido durante dois anos seqüenciais (2003 e 2004). Cada ano foi dividido em duas fases: na fase 1, em ambos os anos (período de outono/ inverno), foram implantadas as culturas de aveia (isolada) e trevo (isolado) e, na fase 2, durante o período de primavera/verão dos anos 2003/04 e 2004/05, sobre resíduo da cultura antecessora oriunda da fase 1 de cada ano, foi cultivado o milho para avaliação do efeito residual das duas espécies forrageiras hibernais. No primeiro ano (2003), em decorrência da dificuldade de estabelecimento das plantas de trevo, não houve pastejo durante o período de inverno. No inverno de 2004, tanto o trevo como a aveia foram pastejados por vacas holandesas. 
Tabela 1 - Características químicas do solo, em três profundidades, antes da instalação do experimento Table 1 - Soil chemical analyses in three depths, prior to the experimental installation

\begin{tabular}{|c|c|c|c|c|c|c|c|c|c|c|c|}
\hline $\begin{array}{l}\text { Prof. } \\
\text { Depth }\end{array}$ & $\mathrm{pH}$ & $\begin{array}{c}\mathrm{MO}^{1} \\
\mathrm{OM}\end{array}$ & $\mathrm{Al}^{+3}$ & $\mathrm{H}+\mathrm{Al}$ & $\mathrm{Ca}$ & $\mathrm{Mg}$ & $\mathrm{K}$ & $\mathrm{P}$ & $\mathrm{V}^{2}$ & $\mathrm{NO}_{3}^{-}$ & $\mathrm{NH}_{4}{ }^{+}$ \\
\hline $\mathrm{cm}$ & $\mathrm{CaCl}_{2}$ & $\mathrm{~g} / \mathrm{dm}^{3}$ & - & - & $\mathrm{cmol}_{\mathrm{c}} / \mathrm{dm}^{3}$ & 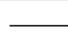 & 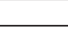 & $\mathrm{mg} / \mathrm{dm}^{3}$ & $\%$ & \multicolumn{2}{|c|}{$\mathrm{mg} / \mathrm{dm}^{3}$} \\
\hline $5-10$ & 5,5 & 47,6 & 0,0 & 5,1 & 7,1 & 3,3 & 1,0 & 5,0 & 69,0 & 119,3 & 227,5 \\
\hline $10-20$ & 5,5 & 44,7 & 0,0 & 5,2 & 7,4 & 2,8 & 0,9 & 2,5 & 68,2 & 104,9 & 206,2 \\
\hline
\end{tabular}

${ }^{1} \mathrm{MO}=$ matéria orgânica (OM = organic matter); ${ }^{2} \mathrm{~V}=$ saturação de bases (Base saturation).

O delineamento experimental foi o de blocos ao acaso, em parcelas subdivididas, com três repetições. As parcelas foram compostas de dois tipos de resíduos de cobertura de inverno (aveia ou trevo) e as subparcelas, de doses crescentes de nitrogênio (0, 60, 120 e $240 \mathrm{~kg} / \mathrm{ha})$, aplicado em cobertura, na forma de uréia, na cultura de milho cultivada sobre o resíduo da cultura antecessora.

No ano de 2003, para implantação das parcelas da fase 1, foi realizada antes do plantio a dessecação da área utilizando-se o herbicida glyphosate (equivalente ácido, $1,5 \mathrm{~L} / \mathrm{ha}$ ) visando à eliminação das ervas daninhas locais. $\mathrm{O}$ plantio da aveia e do trevo foi realizado a lanço no dia 6 de junho de 2003. Depois, foi passada a grade para cobrir as sementes e possibilitar a germinação. Na área com aveia, utilizou-se o cultivar IAPAR 61 em densidade de semeadura de 100 kg/ha e, para a implantação da área de leguminosa, utilizou-se trevo-vermelho (Trifolium pratense), $6 \mathrm{~kg} / \mathrm{ha} \mathrm{e}$ $11 \mathrm{~kg} / \mathrm{ha}$. Como adubação de base, utilizou-se o adubo formulado 0-25-25 + 1\% Zn em quantidade de $250 \mathrm{~kg} / \mathrm{ha}$.

Em 2004, no dia 10 de maio, realizou-se o plantio da aveia por meio de semeadura a lanço e gradagem. A densidade de semeadura do cultivar IAPAR 61 foi de $100 \mathrm{~kg} / \mathrm{ha}$. A adubação de base foi de $250 \mathrm{~kg} /$ ha do adubo formulado 0-20-20. As parcelas de trevo, no entanto, já se encontravam estabelecidas, em virtude do cultivo da leguminosa no ano anterior e da perenidade da espécie.

O pastejo rotativo, em ambas as áreas, foi realizado no inverno de 2004. Os animais foram soltos quando a cultura de aveia atingiu $25 \mathrm{~cm}$ de altura e foram retirados quando a cobertura vegetal apresentava altura média de 10 a $12 \mathrm{~cm}$.

Antes da implantação do milho, nos dois anos de experimento, foi coletada matéria verde de trevo (no estádio vegetativo) e aveia (no estádio de enchimento de grãos) em uma área de $0,25 \mathrm{~m}^{2}$ para avaliação da quantidade de MS por hectare. Em ambos os anos de avaliação, foram coletadas ainda amostras de solo para caracterização química da área nas profundidades de 0 a $5 \mathrm{~cm}$; 5 a $10 \mathrm{~cm}$ e de 10 a $20 \mathrm{~cm}$.

Na fase 2, sobre as parcelas oriundas da fase 1, em ambos os anos, foi cultivado milho para avaliação do efeito residual da fixação biológica de nitrogênio pelas plantas de trevo. Nos anos de 2003 e 2004, o milho foi semeado nos dias 16 de outubro e 1 de outubro, utilizando-se os híbridos DEKALB-215 e DEKALB 566, respectivamente. Em ambos os anos, fez-se uma adubação de base de $300 \mathrm{~kg} / \mathrm{ha}$ de NPK 0-20-20 e o espaçamento entre linhas foi de $90 \mathrm{~cm}$, sendo utilizando-se densidade de 6 sementes $/ \mathrm{m}$.

Para aplicação das doses crescentes de N, como tratamento das subparcelas, em ambos os anos, metade da dose de uréia foi aplicada quando o milho atingiu o estádio de 5 a 6 folhas, e a outra metade, de 10 a 12 folhas, perfazendo um total de $0,60,120$ e $240 \mathrm{~kg} / \mathrm{ha}$, conforme os tratamentos programados.

A amostragem de solo para caracterização química da área experimental foi realizada no primeiro ano do experimento. No segundo ano de avaliação, foram realizadas coletas de solo para análise de rotina antes do plantio de milho e outra aos 120 dias após a emergência (DAE). Cada ponto de coleta foi estratificado em três profundidades ( 0 a 5; 5 a 10; e 10 a $20 \mathrm{~cm}$ ). As amostras foram encaminhadas para análise de solo, realizada no Laboratório de Análises de Solos do IAPAR/UTFPR.

$\mathrm{Na}$ análise dos teores de nitrato, a metodologia de coleta das amostras foi idêntica à descrita anteriormente, porém em sete momentos distintos. Durante o experimento no período 2003/2004, foram realizadas sete coletas: a primeira no outono (31/05/04), no momento do plantio da aveia; a segunda, durante o período de pastejo (20/08/04); a terceira, no plantio de milho (01/10/04); a quarta, aos 30 dias após a emergência (DAE) do milho; a quinta, aos 60 DAE; a sexta, aos 90 DAE; e a sétima, aos 120 DAE. As amostras foram encaminhadas ao Laboratório de Análise Química e Física do Solo no IAPAR de Londrina - PR. Os teores de nitrato foram determinados pelo método Kjeldahl (EMBRAPA, 1999).

A produtividade de grãos de milho ( $\mathrm{kg} / \mathrm{ha}$ ) foi determinada em uma área útil de 16,1 m², depois da correção da umidade para $13 \%$.

A máxima eficiência técnica (MET) foi obtida a partir do ponto de máxima de uma equação de segundo grau, calcu- 
lado igualando-se a zero a derivada de primeira da equação e encontrando-se posteriormente o valor de $\mathrm{x}$, conforme equação a seguir:

$$
\begin{gathered}
\mathrm{Y}=\mathrm{a}+\mathrm{bx}-\mathrm{cx}^{2} \\
\frac{d Y}{d X}=b-2 c x \rightarrow x=\frac{b}{2 c}
\end{gathered}
$$

Os fatores de rendimento foram obtidos contando-se o número de espigas por parcela e pesando-se uma amostra de 400 grãos de milho por parcela. Por meio da relação destes critérios com o rendimento de grãos de milho por parcela, obtiveram-se o peso de mil grãos, o peso de espiga e o número de grãos por espiga.

Os resultados das avaliações foram submetidos à análise de variância. As variâncias foram avaliadas quanto à homogeneidade pelo teste de Bartlett e as variáveis que se mostraram homogêneas foram avaliadas pelo teste $\mathrm{F}$. Quando os resultados revelaram significância a 5 ou 1\% de probabilidade, as médias do fator qualitativo (cobertura vegetal de inverno) foram comparadas pelo teste Tukey a $5 \%$ de probabilidade. Para o fator quantitativo (dose de $\mathrm{N}$-verão), foram ajustadas regressões polinomiais entre os níveis de $\mathrm{N}$ (variável independente) e as demais variáveis dependentes buscando-se o modelo que melhor expressasse essa relação. Foram testados modelos linear e quadrático e a escolha foi baseada na significância (menor que $7 \%$ ) e no coeficiente de determinação.

\section{Resultados e Discussão}

No ano de 2003, em decorrência da baixa produtividade inicial da cultura do trevo, não foi possível realizar o pastejo das forrageiras de inverno. Para implantação da cultura de milho, as parcelas cultivadas com trevo apresentaram, em média, MS residual de $4.579 \mathrm{~kg} / \mathrm{ha} \mathrm{e,} \mathrm{para} \mathrm{as}$ parcelas cultivadas com aveia, a MS residual foi o dobro (9.402 kg/ha).
Como no inverno de 2004 houve pastejo das forrageiras, a quantidade de resíduo das culturas de aveia e trevo que restou sobre o solo para o plantio do milho foi semelhante. Para o trevo, a quantidade de MS residual estimada foi de $2.865 \mathrm{~kg} / \mathrm{ha}$ e para aveia, de $2.703 \mathrm{~kg} / \mathrm{ha}$. Esses valores foram superiores ao recomendado por Assmann et al. (2003) para implantação sob sistema de plantio direto de culturas de verão em integração lavourapecuária e levemente inferiores aos $3.000 \mathrm{~kg} / \mathrm{ha}$ recomendados por Cassol (2003).

No segundo ano de cultivo, no momento do restabelecimento das forrageiras de inverno (outono/2004), os teores de $\mathrm{N}$-nitrato foram influenciados pela interação resíduo da cultura inverno $\times$ profundidade da amostra.

As parcelas cultivadas com trevo apresentaram na camada superficial do solo (0 a $5 \mathrm{~cm}$ ), maiores teores de $\mathrm{N}$-nitrato se comparadas àquelas cultivadas com aveia (Tabela 2). Provavelmente esta diferença foi provocada pela morte e decomposição de nódulos e da parte aérea das plantas de trevo estabelecidas no ano anterior a coleta.

Posteriormente, durante o pastejo, as diferenças provocadas pelo tipo de cultura de inverno não influenciaram os teores de $\mathrm{N}$-nitrato, que foram afetados apenas pela profundidade do solo. Possivelmente, a inclusão de resíduos animais (fezes e urina) no sistema acelerou a decomposição da palhada de aveia em comparação à dos trevos, fazendo com que a disponibilidade de $\mathrm{N}$ fosse equivalente nas duas culturas.

No momento do plantio da cultura do milho 2004/2005, as parcelas cultivadas com trevo e pastejadas voltaram a apresentar maiores teores de N-nitrato na profundidade de 0-5 cm quando comparadas às parcelas cultivadas com aveia; nas profundidades inferiores, o efeito do tipo de cobertura não prevaleceu e os teores de $\mathrm{N}$-nitrato foram iguais, independentemente do resíduo da cultura anterior.

O efeito da interação resíduo da cultura antecessora $x$ profundidade de solo manteve-se durante todo o período

Tabela 2 - Teores de N-nitrato no solo durante os anos de 2004 e 2005

\begin{tabular}{|c|c|c|c|c|c|}
\hline & \multicolumn{2}{|c|}{$\begin{array}{c}\text { Plantio outono } 2004 \\
\text { Fall seedling } 2004\end{array}$} & \multirow[t]{2}{*}{$\begin{array}{cc}\text { Pastejo } 2004 \\
\text { Grazing } 2004\end{array}$} & \multicolumn{2}{|c|}{$\begin{array}{l}\text { Plantio milho 2004/2005 } \\
\text { Corn seedling 2004/2005 }\end{array}$} \\
\hline & $\begin{array}{l}\text { Aveia } \\
\text { Oat }\end{array}$ & $\begin{array}{l}\text { Trevo } \\
\text { Clover }\end{array}$ & & $\begin{array}{c}\text { Aveia } \\
\text { Oat }\end{array}$ & $\begin{array}{c}\text { Trevo } \\
\text { Clover }\end{array}$ \\
\hline $\begin{array}{l}\text { Profundidade }(\mathrm{cm}) \\
\text { Depth }\end{array}$ & & & $\begin{array}{c}\mathrm{N} \text {-nitrato }(\mathrm{mg} / \mathrm{kg}) \\
N \text {-nitrate }\end{array}$ & & \\
\hline $\begin{array}{l}0-5 \\
5-10 \\
10-20\end{array}$ & $\begin{array}{c}37,9 \mathrm{bA} \\
21,9 \mathrm{aB} \\
19,7 \mathrm{aB}\end{array}$ & $\begin{array}{l}55,3 \mathrm{aA} \\
25,2 \mathrm{aB} \\
20,0 \mathrm{aB}\end{array}$ & $\begin{array}{l}22,8 \mathrm{~A} \\
17,0 \mathrm{~B} \\
13,7 \mathrm{C}\end{array}$ & $\begin{array}{c}22,8 \mathrm{bA} \\
17,2 \mathrm{aB} \\
20,1 \mathrm{aB}\end{array}$ & $\begin{array}{c}36,6 \mathrm{aA} \\
17,7 \mathrm{aB} \\
14,8 \mathrm{aB}\end{array}$ \\
\hline
\end{tabular}

Table 2 - $\quad$ N-nitrate soil concentration in 2004 and 2005

Médias seguidas de letras iguais, minúsculas em mesma linha e maiúsculas em mesma coluna, não diferem $(P \leq 0,05)$ pelo teste Tukey. Means followed by the same letter, lower case letter within the row and capital letter within the column, are not significantly different $(P \leq 0.05)$ by Tukey test. 
de cultivo da cultura do milho 2004/2005; sempre as parcelas contendo resíduo de trevo, em todas as datas de amostragem, na profundidade de $0-5 \mathrm{~cm}$, apresentaram maiores teores de $\mathrm{N}$-nitrato em comparação àquelas parcelas cultivadas com aveia (Tabela 3), indicando que a cultura de milho teria praticamente todas suas necessidades de adubação nitrogenada supridas pelo cultivo anterior do trevo branco pastejado.

Em todos os momentos de amostragem do solo (Tabelas 2 e 3) não foram constatados indícios de lixiviação provocados pelo cultivo da leguminosa pastejada. Os teores de $\mathrm{N}$-nitrato observados nas camadas inferiores do solo foram estatisticamente iguais, independentemente do tipo da espécie de pastagem cultivada anteriormente.

Aumentos de produção de carboidratos pela planta contribuem para maior produtividade total (enchimento de grãos) apenas se a capacidade de armazenamento (número de grãos) da planta for máxima. No caso de cereais, significa a necessidade de que adequado número de grãos seja produzido para que esses grãos sejam capazes de receber carboidratos originários do metabolismo das plantas.

Neste fato reside a importância do número de grãos por espiga e do peso individual de grãos. De modo geral, fatores que atuam sobre os estádios vegetativos das plantas de milho, nos momentos iniciais da emergência, influenciarão principalmente o número de grãos por espiga, enquanto o tamanho do grão é afetado por fatores que atuam após a antese. O número de grãos por espiga pode ser afetado significativamente por pequenas quantidades de $\mathrm{N}$ aplicado em estádios precoces de plantio, quando as plantas apresentam alturas inferiores a $20 \mathrm{~cm}$ (Arnon, 1974).

O número de grãos por espiga neste experimento foi influenciado pela interação resíduo da cultura antecessora $\mathrm{x}$ doses de $\mathrm{N}(\mathrm{P}=0,0023)$. O número médio de grãos de milho por espiga das plantas de milho cultivadas sobre resíduos de trevo foi 492 e não foi afetado pelas aplicações de $\mathrm{N}$ em cobertura na cultura de milho (Figura 1). Para as plantas

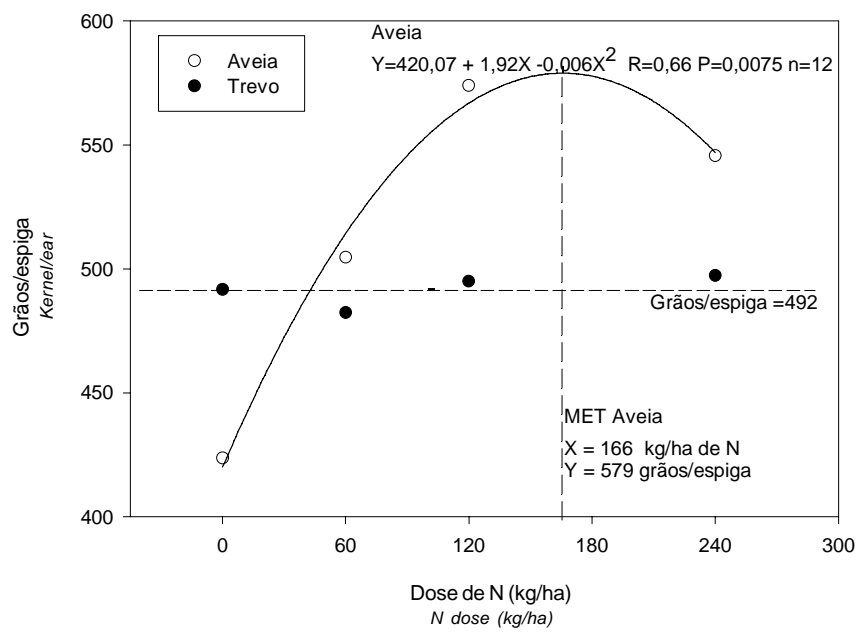

Figura 1 - Número de grãos por espiga em cultura de milho adubada com nitrogênio em cobertura cultivada em resíduo de uma cultura antecessora.

Figure 1 - Kernel by ear in maize crop fertilized with broadcasted nitrogen and cultivated in soil with residue of previous crop.

cultivadas sobre resíduos de palhada de aveia, este valor foi afetado pela aplicação de $\mathrm{N}$ em cobertura e variou em média de 424 (quando não foi aplicado N) a 579 grãos por espiga (com a aplicação de $\mathrm{N}$ - $166 \mathrm{~kg} / \mathrm{ha}$, ponto de máxima eficiência técnica para esta variável).

Como as plantas cultivadas sobre os diferentes resíduos de materiais (aveia e trevo) receberam o nitrogênio em cobertura no mesmo momento, presume-se que a limitação do número de grãos observada nas parcelas com resíduo de trevo tenha sido causada por fatores que atuaram nos estádios mais precoces da cultura.

Embora plantas de trevo sejam classificadas como plantas de desenvolvimento hibernal, sabe-se que continuam a vegetar durante o período de primavera/verão. Mesmo que estas plantas tenham sido pastejadas durante o período de outono/inverno, no momento da implantação, as plantas de trevo provavelmente competiram com as plantas de milho que se encontravam emergindo, enquanto que as parcelas

Tabela 3 - Teores de N-nitrato no solo durante o cultivo do milho no verão 2004/2005

Table 3 - $\quad \quad \quad N$-nitrate soil concentration during the maize cropping of 2004/2005

\begin{tabular}{|c|c|c|c|c|c|c|c|c|}
\hline \multirow{3}{*}{$\begin{array}{l}\text { Prof. (cm) } \\
\text { Depth }\end{array}$} & \multicolumn{2}{|c|}{30 DAE* } & \multicolumn{2}{|c|}{$60 \mathrm{DAE}$} & \multicolumn{2}{|c|}{$90 \mathrm{DAE}$} & \multicolumn{2}{|c|}{$120 \mathrm{DAE}$} \\
\hline & Aveia & Trevo & Aveia & Trevo & Aveia & Trevo & Aveia & Trevo \\
\hline & Oat & Clover & Oat & Clover & Oat & Clover & Oat & Clover \\
\hline $0-5$ & $42,1 \mathrm{bA}$ & $59,5 \mathrm{aA}$ & $41,9 \mathrm{bA}$ & $76,1 \mathrm{aA}$ & $26,2 \mathrm{bA}$ & $44,6 \mathrm{aA}$ & $9,0 \mathrm{bA}$ & 18,9 a $\mathrm{A}$ \\
\hline $5-10$ & $23,9 \mathrm{aB}$ & $27,8 \mathrm{aB}$ & $21,8 \mathrm{bB}$ & $33,7 \mathrm{aB}$ & $17,3 \mathrm{aAB}$ & $20,1 \mathrm{aB}$ & $8,5 \mathrm{aA}$ & $11,1 \mathrm{aB}$ \\
\hline
\end{tabular}

Médias seguidas de letras iguais, minúsculas em uma mesma linha e maiúsculas em uma mesma coluna, não diferem (P $\leq 0,05)$ pelo teste Tukey.

Means followed by the same letter, lower case letter within the row and capital letter within the column, are not significantly different (P $\leq 0.05)$ by Tukey test.

*DAE = Dias após emergência (Days after emergency). 
de aveia, não apresentavam plantas vegetando no momento do plantio e emergência da cultura do milho.

A competição por distintos fatores (água, nutrientes, luz) pode ter resultado em menor número de grão por espiga. Eck (1986) verificou que déficits de água durante o período de crescimento vegetativo reduziram o número de grãos, mas tiveram pequeno efeito sobre o peso por grão de milho. Harder et al. (1982) constataram que o número de grãos por espiga foi influenciado por estresse em estádios de desenvolvimento precoce da cultura, porém o estresse teve pouca influência no peso dos grãos.

O peso individual de cada grão foi influenciado pelas doses de $\mathrm{N}$ aplicadas em cobertura na cultura do milho ( $\mathrm{P}=0,0053)$, independentemente do resíduo da cultura antecessora (Figura 2), uma vez que esta variável é mais influenciada por fatores que atuam mais tardiamente. Observa-se que com a dose de $195 \mathrm{~kg} / \mathrm{ha}$ obteve-se o maior peso de mil grãos (361 g).

Bortolini et al. (2001) encontraram resultado semelhante e observaram maior peso de mil grãos e número de grãos por espiga com adubações nitrogenadas de $150 \mathrm{~kg} / \mathrm{ha}$.

O peso de uma espiga de milho, de maneira simplificada, pode ser resultante de dois fatores básicos, do número de grãos desta espiga e do peso individual destes grãos. Embora o enchimento de grãos tenha ocorrido de forma homogênea em decorrência das doses de $\mathrm{N}$ aplicadas em cobertura na cultura do milho, esta igualdade não foi suficiente para compensar a diferença inicial provocada pelo número de grãos. Assim, o peso por espiga foi influenciado pela interação resíduo da cultura antecessora $\mathrm{x}$ doses de $\mathrm{N}$ ( $\mathrm{P}=0,0019)$ (Figura 3). Do mesmo modo que as doses de $\mathrm{N}$

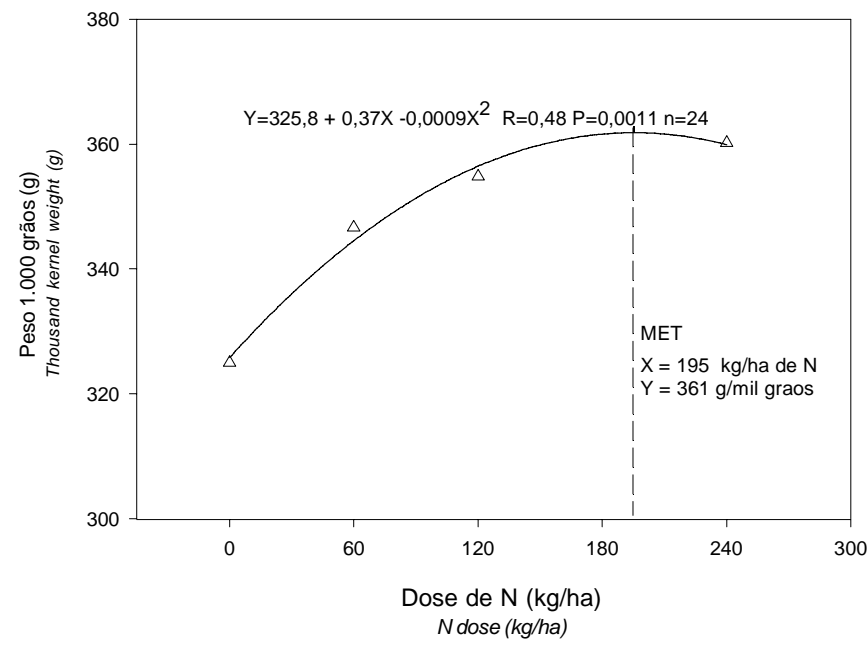

Figura 2 - Peso de mil grãos por espiga em cultura de milho adubada com nitrogênio.

Figure 2 - $\quad$ Thousand kernel weight in a maize crop fertilized with $\mathrm{N}$. não influenciaram o número de grãos das espigas das parcelas que continham resíduo de trevo, a aplicação de $\mathrm{N}$ nestas parcelas não influenciou o peso das espigas.

Para as plantas de milho cultivadas sobre resíduo de aveia, o peso das espigas foi influenciado pela aplicação de N; o peso máximo obtido por espiga foi de 212 g com a aplicação de $\mathrm{N}$ em dose de $171 \mathrm{~kg} / \mathrm{ha}$. Como visto anteriormente, estas parcelas já apresentavam potencial maior de produtividade por apresentarem maior número de grãos por espiga, o que provocou maior demanda por carboidratos resultando em maior peso de espigas em comparação às plantas cultivadas sobre resíduos de trevo, que apresentavam menor número de grãos diferidos por espiga.

No primeiro período de verão de avaliação do experimento (2003/04), a produtividade de grãos de milho foi influenciada apenas pelas doses crescentes de $\mathrm{N}$ de cobertura aplicadas na cultura de verão, independentemente se o resíduo da cultura antecessora foi de trevo ou de aveia (Figura 4). A máxima eficiência técnica (MET) para aplicação de $\mathrm{N}$ em cobertura foi obtida com a dose de $183 \mathrm{~kg} / \mathrm{ha}$ de $\mathrm{N}$, o que correspondeu a uma produtividade de $10.660 \mathrm{~kg} /$ ha de grãos de milho.

Aumentos de produtividade de grãos de milho provocados por aplicação de doses de $\mathrm{N}$ em cobertura nas parcelas cultivadas sobre resíduos de planta de trevo poderiam indicar que estas plantas não estariam fixando $\mathrm{N}$ ou, então, que o $\mathrm{N}$ fixado pela leguminosa não foi disponibilizado à cultura de milho em tempo hábil para absorção, provavelmente em virtude da menor velocidade para estabelecimento de plantas de trevo no seu primeiro ano de cultivo.

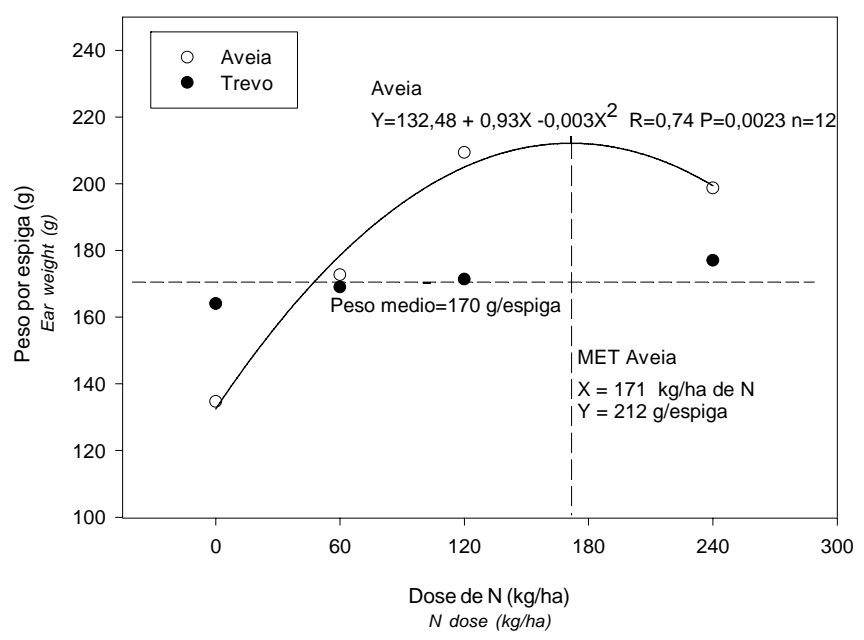

Figura 3 - Peso de espiga em cultura de milho cultivada sobre resíduo da cultura antecessora e adubada com nitrogênio em cobertura.

Figure 3 - Ear weight in a maize crop cultivated on soil with previous crop residue and fertilized with broadcasted $N$. 


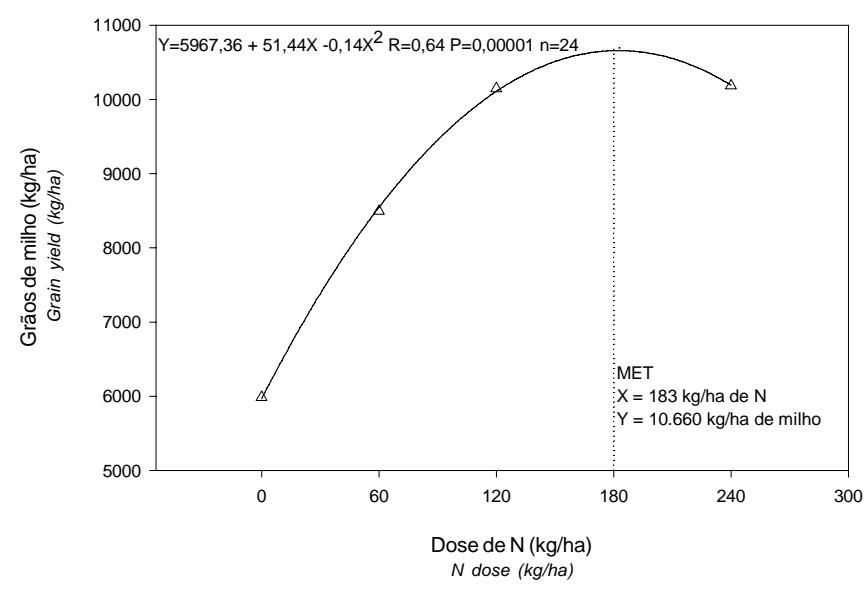

Figura 4 - Produtividade da cultura do milho adubada com nitrogênio em cobertura.

Figure 4 - Grain yield in maize crop fertilized with broadcasted N.

Para o cultivo de 2004/05, observou-se influência da interação resíduo da cultura antecessora $\mathrm{x}$ doses de $\mathrm{N}$ verão $(\mathrm{P}<0,001)$ sobre a produtividade da cultura de milho. A aplicação de doses crescentes de $\mathrm{N}$ em cobertura em plantas de milho cultivadas sobre o resíduo de plantas de trevo não promoveu aumentos na produtividade, que, em grãos de milho, foi de $10.529 \mathrm{~kg} / \mathrm{ha}$, independentemente da dose de $\mathrm{N}$ aplicada (Figura 5).

O fato de as plantas de milho cultivadas sobre parcelas de trevo não terem atingido potenciais de produtividade elevados pode ser atribuído à competição provocada pelas plantas de trevo que se encontravam vegetando. Nordquist \& Wicks (1974) cultivaram milho para silagem com alfafa e constataram reduções na produtividade de milho que variaram de 20 a 50\%, em virtude da competição. Segundo Scott et al. (1987), a produtividade de grãos de milho é dificilmente prejudicada pela competição quando outras espécies são semeadas com uma defasagem de tempo até que o milho atinja 15 a $30 \mathrm{~cm}$ de altura.

Em estudo de rotação de culturas, com milho seguindo consórcio, ou cultivo isolado de centeio/leguminosa, não pastejado, Karpenstein-Machan e Stuelpnagel (2000) constataram que a maior produtividade de MS de milho foi obtida na seqüência do cultivo isolado de ervilha forrageira (Pisum sativum L.) e que a aplicação de $\mathrm{N}$ na cultura do milho não provocou aumentos de produtividade. Quando o milho que não recebeu adubação nitrogenada foi cultivado sob as parcelas que continham resíduo de consórcio centeio/ervilha, a produtividade foi menor que a de parcelas cultivadas sobre o resíduo exclusivo de leguminosa, contudo, a aplicação de adubação nitrogenada pode ser usada para equalizar a diferença de produtividade.

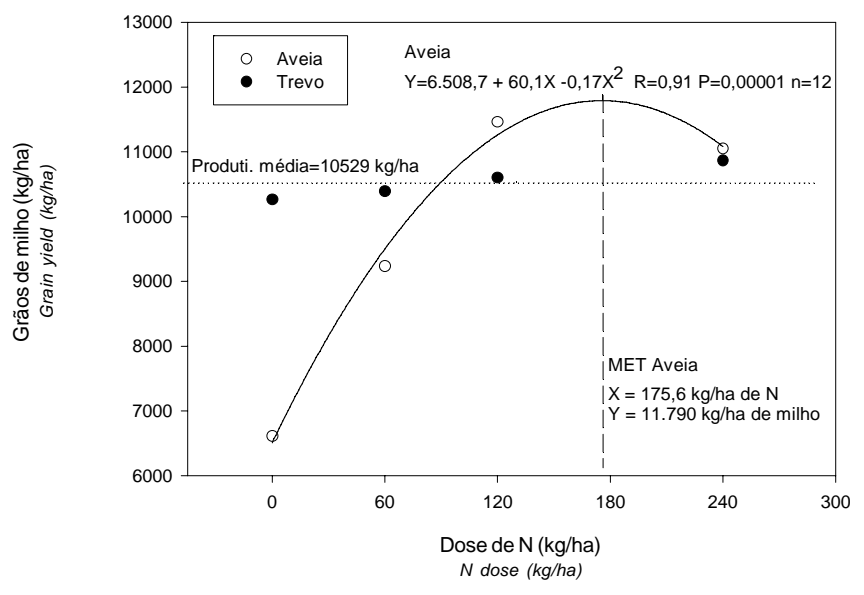

Figura 5 - Produtividade de grãos de milho em cultura cultivada sobre resíduos de uma cultura antecessora e adubada com doses crescentes de nitrogênio

Figure 5 - Grain yield in maize crop cultivated in soil with different crop residues and fertilized with broadcasted $N$.

As plantas de milho cultivadas sobre resíduos de palhada de aveia apresentaram resposta significativa, quanto à produtividade, à dose de $\mathrm{N}$ aplicada no verão. A máxima eficiência técnica (MET) foi obtida com a aplicação de $\mathrm{N}$ na dose de 175,6 kg/ha, que corresponde a uma produtividade de $11.790 \mathrm{~kg} /$ ha de grãos de milho (Figura 5).

Utilizando a equação de rendimento de grãos de milho em função das doses de $\mathrm{N}$ aplicadas no milho cultivado sobre os resíduos de aveia e considerando a produtividade média de milho cultivado sobre os resíduos de trevo (10.529 kg/ha de milho), conclui-se, de forma indireta, que o processo de fixação biológica de $\mathrm{N}$ pelas plantas de trevo contribui com uma quantidade de aproximadamente 90 kg/ha. Provavelmente, o valor disponível de N no solo resultante da fixação biológica de $\mathrm{N}$ por plantas de trevo seja superior a este valor estimado, uma vez que a competição inicial provocada pela leguminosa sobre as plântulas de milho limitou a capacidade de repostas ao $\mathrm{N}$ em razão do menor número médio de grãos de milho formados nos estádios mais precoces.

Trabalho semelhante foi desenvolvido por Bortolini et al. (2001) em Argissolo Vermelho distrófico típico, texturaargilosa. Esses autores obtiveram $11.000 \mathrm{~kg} / \mathrm{ha}$ de grãos de milho com dose de $180 \mathrm{~kg} / \mathrm{ha}$ de $\mathrm{N}$ e $6.920 \mathrm{~kg} / \mathrm{ha}$ com a dose $0 \mathrm{~kg} / \mathrm{ha}$. Ferreira et al. (2001), em Argissolo VermelhoAmarelo distrófico com teor de MO de 17,5 g/kg, observaram resultados semelhantes para a dose $0 \mathrm{~kg} / \mathrm{ha} \mathrm{N}$ e obtiveram $6.200 \mathrm{~kg} / \mathrm{ha}$. Para a dose de $\mathrm{N}$ de $210 \mathrm{~kg} / \mathrm{ha}$, no entanto, obteviveram $8.638 \mathrm{~kg} / \mathrm{ha}$.

Como esta área está há mais de dez anos sob sistema de plantio direto com rotação de culturas entre gramíneas e leguminosas, provavelmente esteja ocorrendo constante 
mineralização da MO, o que supre parte do nitrogênio exigido pela cultura. Em contraste, o baixo rendimento de grãos nas parcelas cultivadas sobre resíduo de aveia e que receberam 0 e $60 \mathrm{~kg} /$ ha de $\mathrm{N}$ pode ser resultado da imobilização do nitrogênio pelos microrganismos que o utilizam para decomposição da palhada de aveia.

Bortolini et al. (2001) encontraram alta relação C/N da palhada de aveia-preta $(35,4)$. Esta relação pode provocar imobilização do $\mathrm{N}$ do solo e diminuir sua disponibilidade para as plantas de milho cultivado em sucessão, principalmente no início do desenvolvimento e, conseqüentemente, reduzir o rendimento de grãos, justificando a necessidade de aplicação de $\mathrm{N}$ em milho cultivado após aveia.

\section{Conclusões}

Plantas de trevo pastejadas podem contribuir com fornecimento de nitrogênio resultante da fixação biológica em sistemas de integração lavoura-pecuária (mínimo $90 \mathrm{~kg} / \mathrm{ha}$ ). Superficialmente, o solo cultivado com a leguminosa apresenta maiores teores de N-nitrato se comparado ao solo cultivado com aveia. Desconsiderando o efeito da leguminosa, a máxima eficiência técnica (MET) da aplicação de doses crescentes de $\mathrm{N}$ sobre a produtividade de grãos de milho foi obtida com a aplicação de aproximadamente $180 \mathrm{~kg} / \mathrm{ha}$.

\section{Literatura Citada}

ARMSTRONG, R.D.; PROBERT, M.E.; McCOSKER, K. et al. Fluxes of nitrogen derived from plant residues and fertiliser on a cracking clay in a semi-arid environment. Australian Journal of Agriculture Research, v.49, p.437-449, 1998.

ARNON, I. Mineral nutrition of maize. Bern-Worblaufen: International Potash Institute, 1974. 452p.

ASSMANN, A.L.; PELISSARI, A.; MORAES, A. et al. Produção de gado de corte e acúmulo de matéria seca em sistema de integração lavoura-pecuária em presença e ausência de trevo branco e nitrogênio. Revista Brasileira de Zootecnia, v.33, n.1, p3347, 2004.

ASSMANN, T.S.; RONZELLI JR., P.; MORAES, A. et al. Rendimento de milho em área de integração lavoura-pecuária sob o sistema plantio direto, em presença e ausência de trevo branco, pastejo e nitrogênio. Revista Brasileira de Ciência do Solo, v.27, n.4, p.675-683, 2003.

BOLLER, B.C.; NÖSBERGER, J. Symbiotically fixed nitrogen from field-grown white and red clover mixed with ryegrasses at low levels of $\mathrm{N}^{15}$ fertilization. Plant and Soil, v.104, p.219-226, 1987.
BORTOLINI, C.G.; SILVA, P.R.F.; ARGENTA, G. et al. Rendimento de grãos de milho cultivado após aveia-preta em resposta a adubação nitrogenada e regime hídrico. Pesquisa Agropecuária Brasileira, v.36, n.9, p.1101-1106, 2001.

CARADUS, J.R. The structure and function of white clover roots systems. Advances in Agronomy, v.43, p.1-46, 1990.

CASSOL, L.C. Relações solo-planta-animal num sistema de interação lavoura-pecuária em semeadura direta com calcário na superfície. Porto Alegre: Universidade Federal do Rio Grande do Sul, 2003. 143p. (Doutorado em Ciência do Solo) - Universidade Federal do Rio Grande do Sul, 2003.

ECK, H.V. Effects of water deficits on yield, yield components and water use efficiency of irrigates corn. Agronomy Journal, v.78, p.1035-1040, 1986.

EMPRESA BRASILEIRA DE PESQUISA AGROPECUÁRIA EMBRAPA. Manual de análises químicas de solos, plantas e fertilizantes. Brasília: 1999. 370p.

FERREIRA, A.C.B.; ARAUJO, G.A.A.; PEREIRA, P.R.G. et al. Características agronômicas e nutricionais do milho adubado com nitrogênio, molibdênio e zinco. Scientia Agrícola, v.58, p.131-138, 2001.

HARDER, H.J.; CARLSON, R.E.; SHAW, R.H. Yield, yield components, and nutrient content of grain as influenced by post-silking moisture stress. Agronomy Journal, v.74, p.275278, 1982.

HOGLUND, J.H.; CRUSH, J.R.; BROCK, J.L. et al. Nitrogen fixation in pasture. 12. General discussion. New Zealand Journal of Experimental Agriculture, v.7, p.45-51, 1979.

KARPENSTEIN-MACHAN, M.; STUELPNAGEL, R. Biomass yield and nitrogen fixation of legumes monocropped and intercropped with rye and rotation effects on subsequent maize crop. Plant and Soil, v.218, p.215-132, 2000.

LEDGARD, S.F.; BRIER, G.J.; UPSDELL, M.P. Effect of clover cultivar on production and nitrogen fixation in clover-ryegrass swards under dairy cow grazing. New Zealand Journal of Agriculture Research, v.33, p.243-249, 1990.

MA, B.L.; DWYER, L.M. Nitrogen uptake and use of two contrasting corn hybrids differing in leaf senescence. Plant and Soil, v.199, p.283-291, 1998.

MAAK, R. Geografia física do estado do Paraná. Curitiba: Banco de Desenvolvimento do Paraná, 1968. 350p.

NORDQUIST, P.T.; WICKS, G.A. Establishment methods for alfalfa in irrigated corn. Agronomy Journal, v.66, p.377-380, 1974

SCHRÖDER, J.J.; NEETESON, J.J.; OENEMA, O. et al. Does the crop or the soil indicate how to save nitrogen in corn production? Reviewing the state of the art. Field Crops Research, v.66, p.151-161, 2000

SCOTT, T.W.; PLESANT, J.; BURT, R.F. et al. Contribution of ground cover, dry matter, and nitrogen from intercrops and cover crops in a corn polyculture system. Agronomy Journal, v.79, p.792-798, 1987.

TA, T.C.; FARIS, M.A. Availability of N from $15 \mathrm{~N}$-labelled alfalfa residues to three succeeding barley crops under field conditions. Soil Biology and Biochemistry, v.22, p.835-838, 1990. 